\title{
The Friction Force Mouse-Pad and the Forearm Muscles Efforts
}

\author{
José Miquel Cabeças*
}

The New University of Lisbon, Faculty of Science and Technology, Quinta da Torre, 2829-516 Caparica, Portugal

\begin{abstract}
The objective of the article is to evaluate the impact of the friction force mouse-pad in the contraction level of the forearm muscles $M$. extensor carpi ulnaris, M. extensor digitorum and M. extensor carpi radialis longus. A standard protocol of mouse movements was performed involving horizontal, vertical and diagonal mouse displacements drag-anddrop type. The operators were instructed to execute the protocol with their normal working speed. The movements protocol were performed by each subject $(n=17)$ with three selected pairs mouse-pad, classified as low, medium and high friction force pairs. The mean time to execute the protocol with each mouse was $\sim 138 \mathrm{~s}$. Mean values of $\sim 13 \% \mathrm{MVE}$ (Maximum Voluntary Electromyography signal), $\sim 17 \% \mathrm{MVE}$ and $\sim 10 \% \mathrm{MVE}$ were found in the M. extensor digitorum, $M$. extensor carpi ulnaris and in the $M$. extensor carpi radialis longus respectively when performing the movements' protocol. A $8.1 \%$ increase in \%MVE was observed in the M. extensor digitorum and a $9.4 \%$ increase in $\% \mathrm{MVE}$ was observed in the $M$. extensor carpi ulnaris when the high friction force pair was operated, relatively to the low friction force pair $(\mathrm{p}<0.05)$. The main conclusions of this study is that operating a high friction force mouse-pad (with $79 \mathrm{~g}$ of static longitudinal friction force measured with a compression force of $100 \mathrm{~g}$ on the mouse) may increase the risk to symptoms or disorders in the wrist, particularly during work with drawing applications, due to an increase in the forearm muscles contraction levels.
\end{abstract}

Keywords: Computer mouse, forearm muscles, EMG, drag-and-drop, friction force mouse-pad.

\section{INTRODUCTION}

The adoption of the graphical user interfaces pointing devices as computer mice, are present in every office environment. In most applications the use of the mouse accounts for almost $60 \%$ of total time, with a maximum level of usage of $65-70 \%$ in drawing applications. Mice are the most frequently used devices among the VDT (Video Display Terminals) users both in term of number of users and in terms of daily time spent in using it [1].

During a comparative study between mouse and nonmouse users, a study by Karlqvist et al., 1994 [2] reported that $64 \%$ of the total mouse working time is spent with more than $15^{\circ}$ cubital deviation. The deviation exceeded $30^{\circ}$ in $30 \%$ of the mouse task time.

Currently, it is uncertain what the exposures to the various mouse-related risk factors are and how the exposures vary between persons, occupations, computer systems and software applications [3]. There is still a lack of knowledge as to the extent to which the use of different input devices influences the activation of the different muscles in the upper limbs [4]. However, there are indications that upper extremities musculoskeletal disorders are related to computer work.

In some studies, mouse use is indicated as a risk factor in computer work [5-7]. The amount of mouse use and the forces applied to the mouse by a computer operator are two

*Address correspondence to this author at the Mechanical and Industrial Engineering Department, The New University of Lisbon, Faculty of Science and Technology, Quinta da Torre, 2829-516 Caparica, Portugal; Tel: +351212949694; E-mail: jmm-cabecas@fct.unl.pt risk factors that may play an important role in the development of musculoskeletal disorders [8].

\subsection{Hand-Wrist Symptoms and Disorders}

The number of studies that have considered the impact of mouse use on musculoskeletal health is limited. Most of these studies only include experiments with small numbers and short-term effects, such as discomfort and muscle activity [9].

Carpal tunnel pressure was measured in 14 healthy individuals while they performed tasks using three different computer mice [10]. All mice were associated with similar wrist extension postures and carpal tunnel pressures. Pressures were significantly greater during dragging and pointing tasks than when resting the hand (static posture) on the mouse. In many participants the carpal tunnel pressures measured during mouse use were greater than pressures known to alter nerve function and structure, indicating that jobs with long periods of intensive mouse use may be at an increased risk of median mononeuropathy. A recommendation was made to minimize wrist extension, minimize prolonged dragging tasks and frequently perform other tasks with the mousing hand.

A study by Jensen, 2003 [11] identified risk factors for musculoskeletal symptoms in the neck and hand-wrist regions among employees using computers at work. The duration of computer use predicted hand-wrist symptoms, but not neck symptoms. For those with almost continual computer use, hand-wrist symptoms were associated with mouse use for at least half of the work time and not using the mouse at all, as compared with mouse use for one-fourth of the work time. Limiting computer use to less than three- 
fourths of the work time would help to prevent hand-wrist symptoms.

One of the objectives of a study developed by Blatter and Bongers, 2002 [12] was to examine the association between work-related upper limb disorders (WRULDs) and duration of computer and particularly mouse use. A population of 5400 office employees had filled out a questionnaire on job characteristics, job content, physical workload, psychosocial workload and musculoskeletal symptoms. Working with a computer during more than $6 \mathrm{~h} / \mathrm{day}$ was associated with WRULDs in all body regions. Frequent computer users who often used a mouse did not report more WRULDs or neck or shoulder disorders than frequent computer users who did not use a mouse. Only for arm, elbow or wrist or hand problems a moderately increased among the mouse users was observed, but this was not statistically significant.

A epidemiological literature was reviewed to evaluate the evidence supporting a causal relationship between computer work and musculoskeletal symptoms and disorders (MSDs) of the hand, wrist, forearm, and elbow [13]. The study concluded that there is consistent evidence of a positive relationship across numerous prospective and cross-sectional studies with increased risk most pronounced beyond 20 hours/week of computer use or with increasing years of computer work. The disorders confirmed with physical examinations are wrist tendonitis and tenosynovitis, medial and lateral epicondylitis, and DeQuervain's tenosynovitis. They concluded that the risk of carpal tunnel syndrome is increased with use of a computer, especially with mouse use for more than 20 hours per week.

A prospective study of computer users (new hired into jobs requiring $\geq 15 \mathrm{hr} /$ week of computer use, $\mathrm{n}=632$ ) was performed by Gerr et al., 2002 [14] to determine the occurrence of and evaluate risk factors for hand and arm (also for neck and shoulders) musculoskeletal symptoms and disorders. The annual incidence of symptoms was 39 cases/100 person-years and of disorders were 21 cases $/ 100$ person-years. The most common disorder was DeQuervain's tendonitis. It was concluded that more than $50 \%$ of computer users reported symptoms during the first year after starting a new job. Any information in this study was particularly oriented to mouse use symptoms and disorders.

The aim of a study developed by Lassen et al., 2004 [15] was to examine relations between computer work aspects and elbow and wrist/hand pain conditions and disorders. A 1-year follow-up study among 6,943 technical assistants and machine technicians self-reported active mouse and keyboard time was associated with elbow and wrist/hand pain. For continuous duration of mouse time, adjusted linear effects were statistically significant for all investigated pain conditions. Detailed examination of self-reported exposures showed that mouse time predicted elbow and wrist/hand pain from low exposure levels without a threshold effect, but mouse time were not predictors of clinical conditions.

\subsection{Finger Forces}

Finger force exposures associated with computer mouse use was measured by Johnson et al., 2000 [3]. The mean forces applied to the sides and button of the mouse were low (range $0.3-6.2 \%$ of maximum voluntary contraction - MVC). According to the authors, it is uncertain whether musculoskeletal disorders can result from these low forces levels. Exposure assessment of computer mouse use in larger scale, real setting is needed to help clarify the role that the various risk factors play in the development of mouse-related musculoskeletal disorders [3].

\subsection{Forearm Muscles Efforts}

Time pressure, precision demands and mental demands affect muscular response during computer work. High time pressure combined with high precision and high mental demand resulted in a higher surface electromyography activity level (EMG) for the extensor digitorum muscle. The reported EMG levels was 7-8\%MVE for this muscle during computer work [16], similar to other laboratory studies during computer work.

The effects of mental and physical demands on muscular activity in the use of the mouse and keyboard in computer work in a time-pressed situation were studied by Laursen $e t$ al., 2000 [4]. EMG data was recorded in the extensor carpi radialis (ECR), flexor carpi radialis (FCR), extensor digitorum (ED) and extensor carpi ulnaris (ECU). The ED muscle had the largest mean EMG (6.3-7.1\%MVE). All the muscles showed increased muscular activity in the mentally demanding condition.

A study developed by Visser et al., 2004 [17] with the objective to gain insight into the effects of precision demands and mental pressure on the load of the upper extremity, revealed that precision demands had a small effect on upper extremity loading with a significant increase in the EMG-amplitudes $(21 \%)$ of the wrist flexors during the aiming tasks. Mental pressure had substantial effects on EMG-amplitudes with an increase of $45 \%$ and $140 \%$ in the wrist extensors and flexors, respectively, when aiming. During aiming, grip- and click-forces increased by $51 \%$ and $40 \%$ respectively.

One of the aims of a study by Bystrom et al., 2002 [18] was to evaluate the physical workload on neck and upper limb in computer-aided design (CAD) work. Muscular load in the left and right forearm extensor muscles was measured during CAD applications "drawing table" with a mouse, in nine operators. In the left and right extensor the values of P10, P50 and P90 \%MVE were respectively 0.9-1.3, 3.7-2.3 and 10.0-3.6 \% MVE.

\section{SUMMARY OF THE METHODOLOGY AND OBJECTIVES OF THE RESEARCH}

The main objective of the research was to understand if the efforts in the forearm muscles are sensitive to the variations in the friction force mouse-pad, or, in other words, to evaluate the effort increase in the forearm muscles as a result of operating mouse-pad pairs with different easiness of displacement. Important mouse movements' drag-and-drop types are performed in drawing applications, as for example by AutoCAD software operators.

Three pairs mouse-pad were selected, representatives of low, medium and high friction force pairs; a protocol of movements was performed with the mice in order to evaluate the compression force exerted by the hand of the operators on the mouse. The friction force mouse-pad was evaluated 
with a compression force exerted on the mouse similar to the compression force exerted by the operators.

A mouse movement's protocol was defined, including vertical, horizontal and diagonal mouse movements, in order to analyze the impact of the friction forces in the forearm muscles contraction.

\section{MATERIALS AND METHODOLOGY}

The following methods where used in the research, in order to evaluate the contraction levels in the forearm muscles when operating different pairs mouse-pad:

1. The compression force of the hand on the computer mouse was evaluated, during a protocol of mouse movements. The objective was to determinate the friction force mouse-pad with a compression force in the mouse similar to the compression force exerted by the operators on the mouse;

2. The static friction force mouse-pad was evaluated in different pairs in use, with the objective to select three representative pairs: low, medium and high friction force pairs;

3. With the objective to normalize the surface electromyography signal (EMG), and to compare results, maximum and sub maximum contraction tests were performed in the right forearm muscles;

4. The contraction levels in the right forearm muscles were evaluated by surface electromyography when performing a protocol of movements with the low, medium and high friction force pairs.

\subsection{The Measurement of Compression Forces of the Hand on the Mice During the Mice Movements Protocol}

To evaluate the compression forces during the work with the three selected mice-pads, the mouse pads were located on a polystyrene (XPS) plate, adapted to the plate of a digital scale.

The protocol of mouse movements represented in Fig. (3) was executed by each subject ( 8 lines by protocol instead of 16 lines), with the forearm supported by a arm-rest at the wrist level, assuring that the compression force measured by

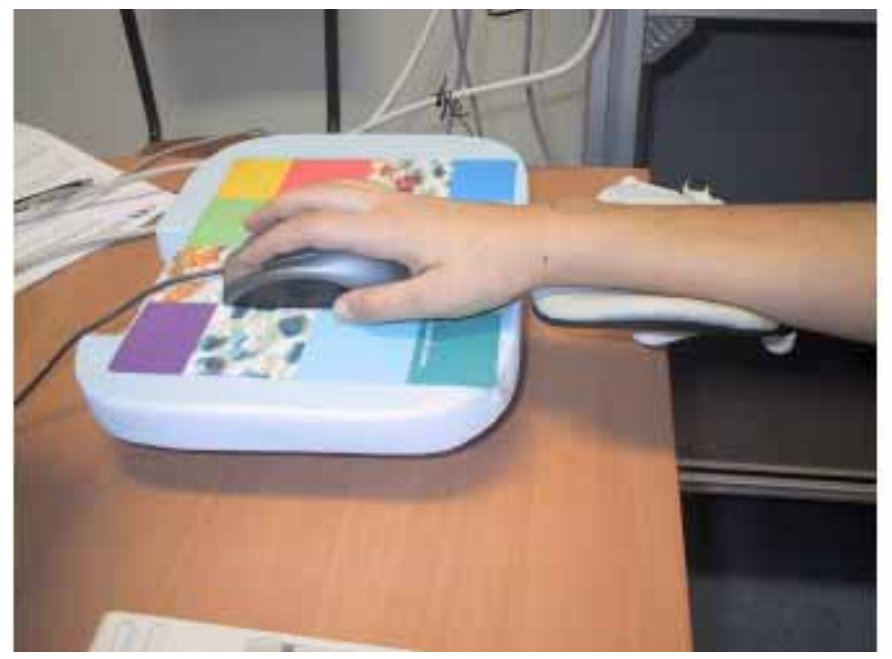

the digital scale is only due to the wrist movements. To each protocol (vertical, horizontal and diagonal) 8 readings were recorded, in the moments when the mouse displacement was in the middle of the segments. Consequently, 24 compression force readings were recorded to each mouse (Fig. 1).

\subsection{The Evaluation of the Static Friction Force Mouse- Pad}

Different types of computer mice and mouse pads are available in the market. The most common and frequent type of mice and mouse pads were selected in this study. Common standard features mice - two or three buttons, with or without a scroll-wheel, mechanical (ball) or optical mouse, cabled mice with PS/2 or USB connectors - were selected. The contact surface of the mice with the pads was linear or curvilinear, circular or elliptical, between two and four contact areas. Other types of mice, as for example, cordless mice, tactile mice or mighty mice were not considered in this study.

All the mice considered in this study were supported by mouse pads. Rubber foam pads, with fabric, jersey, lycra or PVC printed cloth were considered. Rectangular and circular pads were observed. Other types, as for example, silica gel mouse pads or wrist-rest pads were not considered in this study.

The friction force between mouse-pads was measured in 39 different pairs, in effective use in the workplaces. They were randomly selected in a Portuguese university, in different locations, corresponding to workplaces with an intense utilization of computers: research labs (25 micepads), student's computer rooms (6 mice-pads), administrative offices (4 mice-pads) and teacher's offices (4 mice-pads). The users of the selected mice-pads were university students, teachers and administrative workers.

The characteristics of the computer mice are the following ones $(n=39)$ :

- $\quad \mathrm{PS} / 2(\mathrm{n}=25)$ and USB $(\mathrm{n}=14)$ connectivity;

- $\quad$ Ball mice $(n=20)$ and optical mice $(n=19)$ technology;

- Two superior buttons $(\mathrm{n}=27)$, three superior buttons

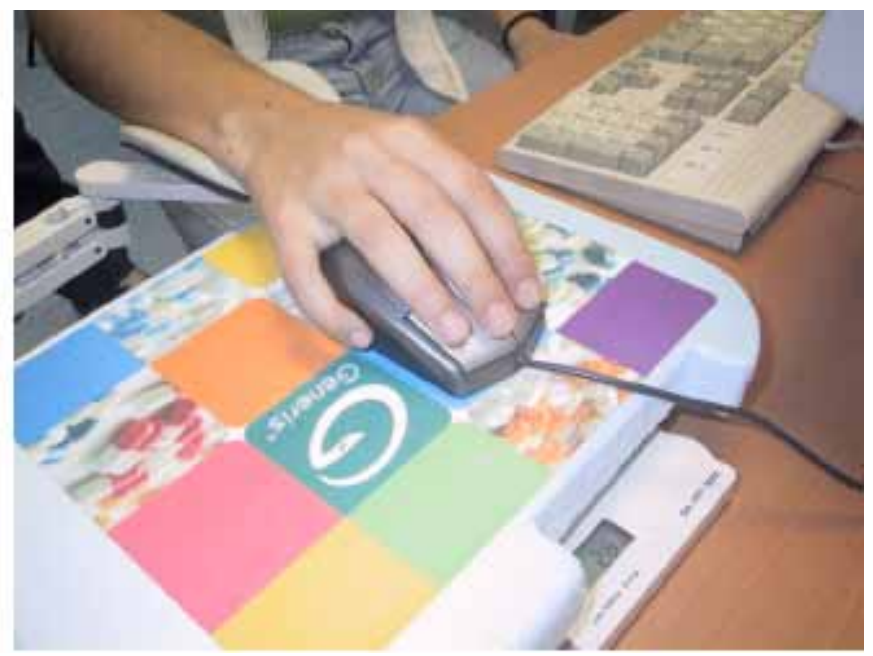

Fig. (1). The measurement of compression forces of the hand on the mice during the mice movements protocol. 
$(n=9)$, lateral buttons $(n=4)$ and one-dimension scroll wheel $(n=29)$ actuators; 20 mice had two superior buttons and a scroll wheel;

- $\quad$ Manufactured in $1994(n=2), 1995(n=1), 1997(n=1)$, $1998(n=3), 1999(n=8), 2000 \quad(n=4), 2001 \quad(n=4)$, $2002(n=3), 2003(n=2), 2004(n=1), 2005(n=1)$, $2006(n=3)$ and $2007(n=6)$;

- Weight 81.0g (26-104, SD=16.4), maximum height $36.0 \mathrm{~mm}$ (24-41, SD=3.8), maximum length 115.1 $\mathrm{mm}(77-126, \mathrm{SD}=10.9)$, maximum width $59.7 \mathrm{~mm}$ (5.6-73, $\mathrm{SD}=10.8)$, width in the button area $57.4 \mathrm{~mm}$ (5.5-65, SD=10.7);

Regarding the contact surface between mice-pads $(n=39)$ :

$\bullet$

Linear or curvilinear contact surface $(n=9)$ with a length of $34.8 \mathrm{~mm}$ length (5-60, $\mathrm{SD}=16.6)$ and a width of $4.4 \mathrm{~mm}(1-7, \mathrm{SD}=1.8)$;

- Four or five circular contact surfaces $(n=14)$ with a diameter of $6.6 \mathrm{~mm}(6-9)$

- Four elliptical contact surfaces $(n=16)$ with major axles length $9-18 \mathrm{~mm}($ mean=14.3) and minor axle length 4-7 $\mathrm{mm}($ mean $=6.1)$;

The characteristics of the mouse pads are the following ones $(n=7)$ :

- Rectangular shape $(n=6)$ with a mean length and width respectively of $237 \mathrm{~mm}$ and $202 \mathrm{~mm}$;

- $\quad$ Circular shape $(\mathrm{n}=1)$ with a diameter of $191 \mathrm{~mm}$;

- $\quad$ Rubber foam $(n=6)$ and PVC foam $(n=1)$ with lycra cloth $(n=1)$ and PVC printed cloth $(n=6)$;

A mechanical device was used to measure the force applied to the mouse, parallel to the pad surface, which initializes the displacement of the mouse (friction force mouse-pad).

A $0.5 \mathrm{~mm}$ nylon wire was carefully attached to the mouse with a $10 \mathrm{~mm}$ Tesa film adhesive band (Fig. 2). A small $2 \mathrm{~g}$ extruded polystyrene (XPS) basket $(40 \times 48 \times 30 \mathrm{~mm})$ was used to receive small lead weights of 8-20-40 g, which were carefully inserted into the basket, until the displacement of

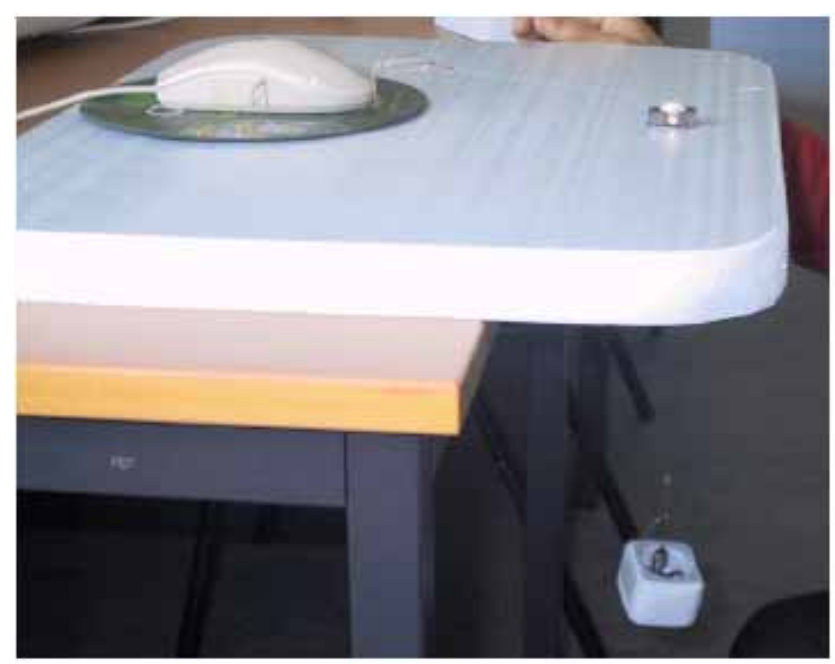

Fig. (2). The measurement of the friction force mouse-pad.

Fig. (2). The measurement of the friction force mouse-pad. the mouse (a plastic $18 \mathrm{~g}$ basket $77 \times 53 \times 45 \mathrm{~mm}$ was used to measure friction force with $100 \mathrm{~g}$ compression force in the mice). Small lead weights with a weight of $0.25 \mathrm{~g}$ were used to refine the measurement. The weight of the polystyrene / plastic baskets with the lead weights, which initialized the displacement of the mouse, was considered the friction static force of the pair mouse-pad in that direction (scale A\&D Co, LTD, Mod. EK-12Ki, max. 12,000 g, d=1g). The friction force was measured in two different directions: (1) the longitudinal force was measured with the nylon wire in the longitudinal direction of the mouse and (2) the transversal force was measured with the nylon wire in the transversal direction of the mouse.

Two groups of friction force measurements were done: (1) With the mice only subjected to their own weight, and (2) with a vertical force of $100 \mathrm{~g}$ applied in the center of the mice.

\subsection{The Mouse Movements Protocol}

To analyze the impact of the different friction forces in the forearm muscles contraction, it was asked the subjects to execute a standard protocol of movements with the three selected mice (low, medium and high friction force pairs mouse-pad). The protocol to each mouse included three groups of movements: (1) vertical ascending and descending movements (2) horizontal left-right and right-left movements and (3) diagonal ascending and descending movements (Fig. 3).

It was created three Microsoft Paint Version 5.1 files (to vertical, horizontal and diagonal movements) with 16 vertical lines, 16 horizontal lines and 16 diagonal lines. To execute the vertical movements, the subjects were instructed to draw a vertical line using the Paint line tool, by first locating the pointer in the location number 1 , pressing and holding down the mouse button and following the existing vertical line with the mouse movement until the end of the line (drag). The mouse button was then released and a vertical line was drawn in the screen, placed on the existing one. Then the mouse pointer was moved to the location number 2 (vertical descending movement), the mousse button pressed and holds, and a second line was drawn

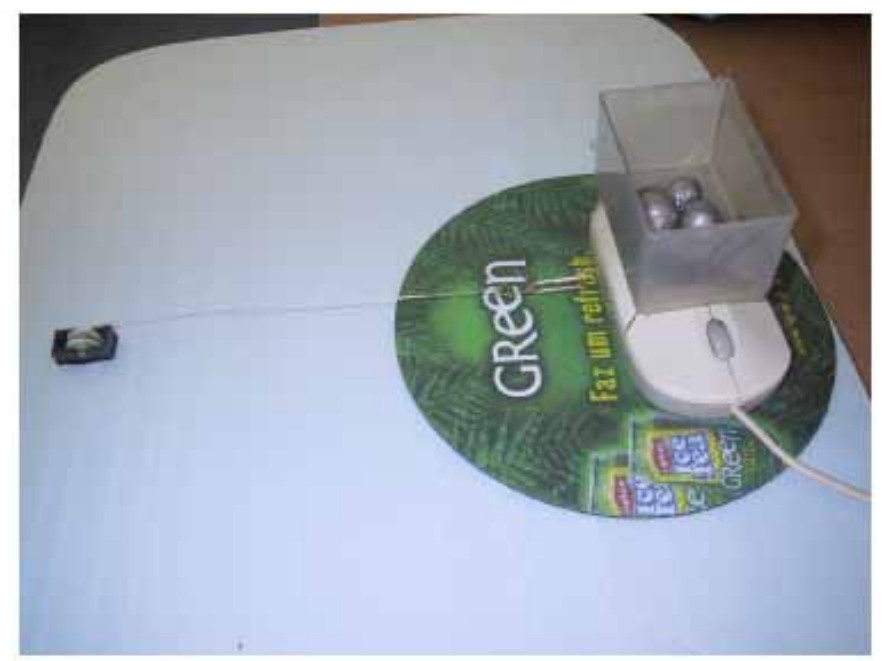




\section{S VERTICAL PROTOCOLO - Windows Picture and Fax Viewer}

Passe o cursor pelas linhas segundo o sentido das setas
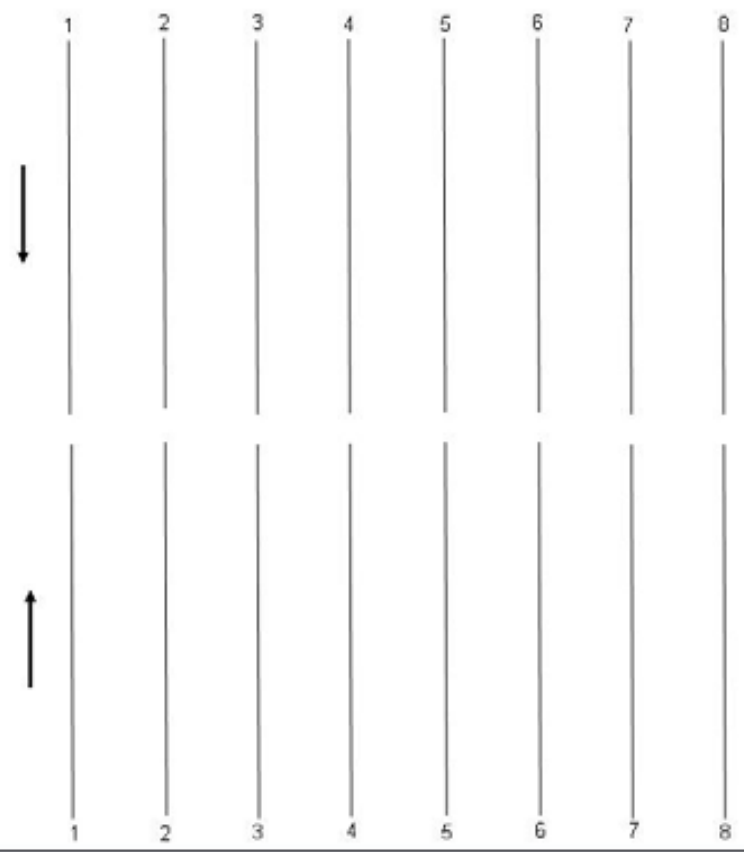

(1)
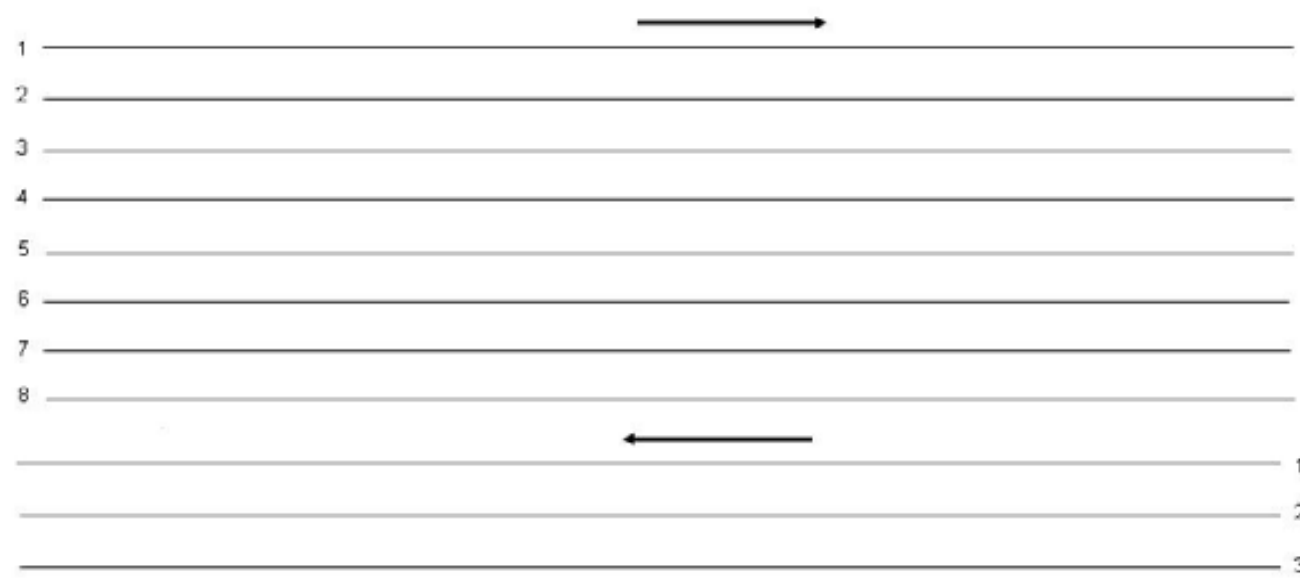
(Fig. 3) contd.....

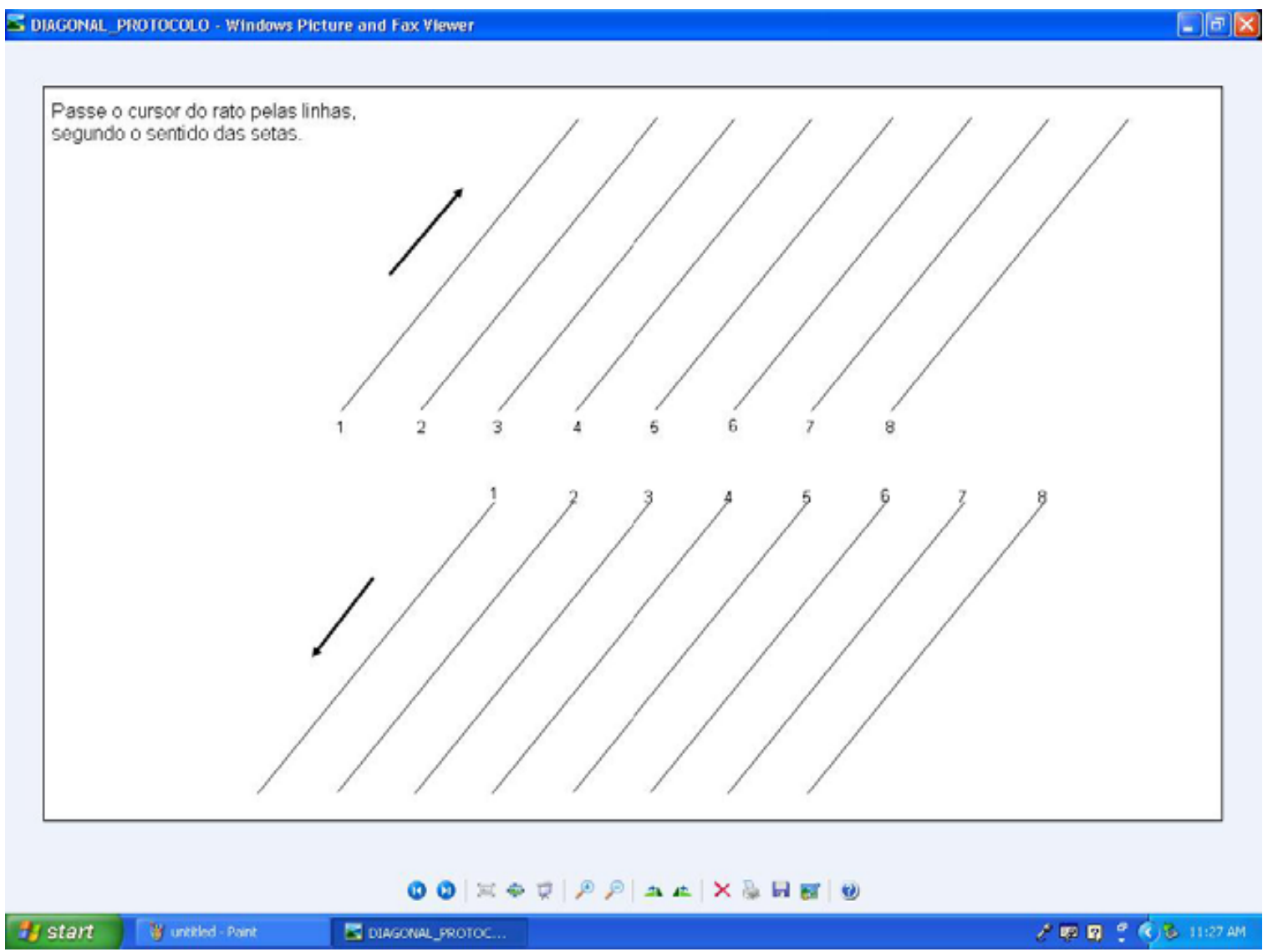

Fig. (3). The mouse movement's protocol: vertical, horizontal and diagonal directions.

placed on the existing one. The movements were repeated to the 8 existing vertical descending lines and then repeated to the next 8 existing vertical ascending lines. The protocol was repeated to the horizontal and diagonal directions. The mean and range times to execute the three directions protocol with each mouse was $137.9 \mathrm{~s}(81-214 \mathrm{~s} ; \mathrm{n}=17)$.

\subsection{The Participants}

Seventeen volunteer engineering students participated in the study (Table 1). All the subjects were familiar with mice utilization; the mean computer working hours with computers during 2007 (January-May) was 367 hours (100840), 787 hours (308-1848) during 2006 and 612 hours (2001848) during 2005; each subject used 3.6 (2-6) different mice during 2007 (period January-May).

The maximum isometric tests were performed with the participants seated, the forearm supported on a table with a $90^{\circ}$ flexed elbow, exerting a power grip in a Hand Dynamometer (Jamar Hydraulic Hand Dynamometer, model 5030J1, Sammons Preston Rolyan USA) and a Pinch Grip in a Pinch Gauge (Jamar Hydraulic Pinch Gauge, model 749805, Sammons Preston Rolyan USA). The grasping distance previously adjusted to the participants' handgrip. Each participant was encouraged to exert a maximum hand and pinch grip during $\sim 5 \mathrm{~s}$, with a rest period of $\sim 1$ min between tests. Three readings were repeated to each measurement.
Table 1. Mean (SD) and Range of Age, Anthropometrics, and Muscular Strength for the Subjects $(n=17)$

\begin{tabular}{|c|c|c|}
\hline Demographic Data & Mean (SD) & Range \\
\hline \hline Female subjects (n) & 10 & ----- \\
\hline Age (years) & $22.5(2.6)$ & $19.0-28.0$ \\
\hline Height $(\mathrm{cm})$ & $172.1(9.6)$ & $156.0-190.0$ \\
\hline Weight $(\mathrm{kg})$ & $67.6(17.3)$ & $48.0-110.0$ \\
\hline Hand grip strength - Right hand $(\mathrm{kg})$ & $38.6(18.9)$ & $19.3-103.3$ \\
\hline Pinch grip strength - Right hand $(\mathrm{kg})$ & $5.2(1.3)$ & $3.0-7.9$ \\
\hline
\end{tabular}

\subsection{Electromyography}

Surface EMG was recorded using disposable bipolar electrodes with a sensor area of $15 \mathrm{~mm}^{2}$, with a skin contact size of $30 \times 22$, placed with a $22 \mathrm{~mm}$ center-to-center distance (Ag/AgCl sensor, Ambu Blue Sensor N, Ambu A/S, Ballerup, Denmark). Data was measured in the right forearm, in the M. extensor digitorum (ED: extends medial four digits at metacarpophalangeal joints and extends hand at wrist joint), M. extensor carpi ulnaris (ECU: extends and adducts/cubical deviation hand at wrist joint), $M$. flexor carpi radialis (FCR: flexes and abducts/radial deviation hand at wrist) and $M$. extensor carpi radialis longus (ECRL: extend 
and abduct/radial deviation hand at wrist joint) (Fig. 4). Results in the $M$. flexor carpi radialis were omitted in this report due to EMG data inconsistency.

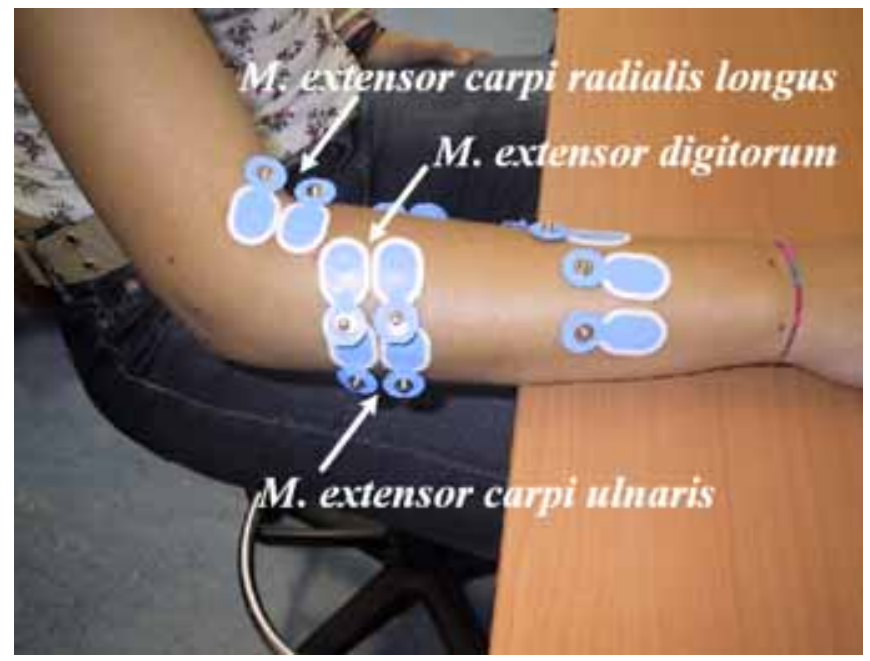

Fig. (4). The location of the EMG electrodes in the forearm.

The skin was carefully prepared over the muscles. In the M. extensor digitorum (ED) the central lead point was located $1 / 4$ distance between lateral epicondyle of humerus and midpoint styloid process of ulna-styloid process of radius with the forearm supported on a table and the palmar surface of the hand on the table $[19,20]$; in the $M$. extensor carpi ulnaris (ECU), the central lead point was located 1/3 distance between midpoint lateral epicondyle of humerus-olecranon and styloid process of ulna with the forearm supported on a table and the palmar surface of the hand on the table $[19,20]$. In the $M$. extensor carpi radialis longus (ECRL), with the elbow at 90 degrees and the forearm in a mid-pronated position, the length of the radius from the lateral epicondyle of the humerus to the styloid process of the radius was measured (A); next, it was measured the distance from the lateral epicondyle of the humerus to the estimated center of the broad origin of the ECRL, in a line along the lateral aspect of the humerus (Ax0.078); finally the distance to the ECRL belly was measured (Ax0.17) from the ECRL origin in a straight line to the styloid process of the radius [21].

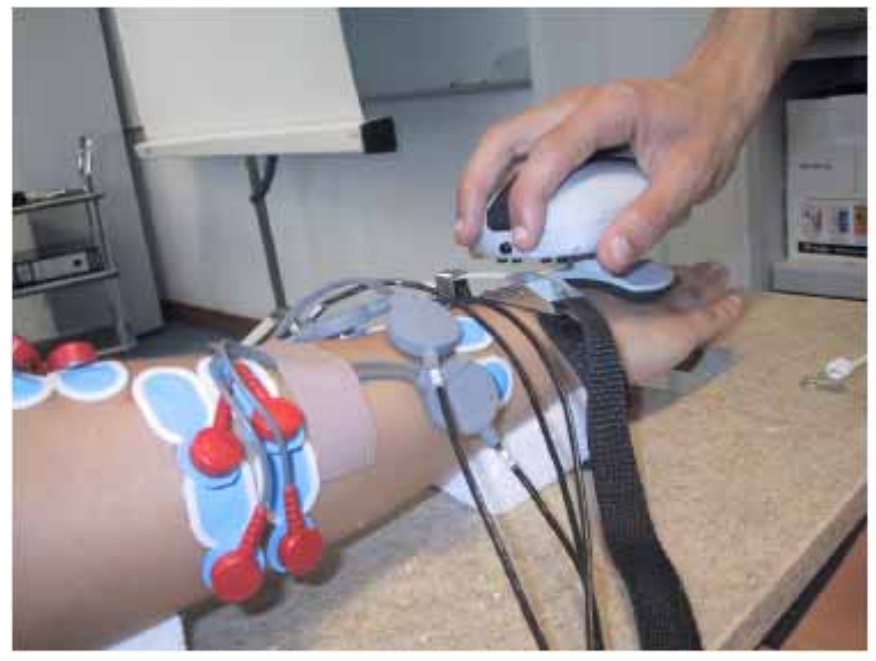

Fig. (5). The maximum isometric tests.

\footnotetext{
Fig. (5). The maximum isometric tests.
}

Data was recorded by a 4-channel Muscle Tester ${ }^{\mathrm{TM}}$ ME6000 (MEGA Electronics Ltd., Kuopio, Finland) with a sampling frequency of $1,000 \mathrm{~Hz}$ and the root-mean-square (RMS) was calculated with a frame width of $100 \mathrm{~ms}$. Data was transferred and stored in a microcomputer with the software MegaWin v.2.3.

\subsubsection{The Maximum Isometric Tests}

The maximum isometric tests were performed with the participants seated in a chair with adjustable height, the forearm resting at wrist and olecranon level in two soft expanded polystyrene (EPS) plates $(70 \times 60 \times 30 \mathrm{~mm})$ supported on a table, with a $90^{\circ}$ flexed elbow and the hand palmar surface down, and extended according to forearm direction. The subjects were instructed to maintain the hand horizontal, face down, extended and aligned with the forearm direction. Three groups of tests were executed: (1) each participant was encouraged to exert a maximum dorsal wrist extension against a Manual Muscle Tester (MMT), (2) each participant was than encouraged to exert a maximum dorsal wrist extension simultaneously with maximum radial wrist deviation against the MMT and finally (3), each participant was encouraged to exert a maximum dorsal wrist extension simultaneously with maximum cubital wrist deviation against the MMT. Three trials of isometric contractions were maintained during $5 \mathrm{~s}$ (pre-set test time), against a rectangular padded stirrups of a MMT (Lafayette Manual Muscle Test System, model 01163, Lafayette Instruments, USA), applied at carpometacarpal joint with the hand and fingers extended according to forearm direction, with a rest period of $\sim 2$ min between trials (Fig. 5). During the tests, EMG data was recorded in the four muscles.

\subsubsection{The Sub Maximal Isometric Tests}

Special equipment was designed to evaluate EMG signal in the different muscles, during sub maximal contraction tests (RVE) (Fig. 6).

A simple mechanism allows applying a constant force in different directions at carpometacarpal joint, with the hand and fingers extended according to forearm direction. With the subjects in the same posture, (1) a constant force of $2 \mathrm{~kg}$ was applied in the vertical direction (to provoke a wrist

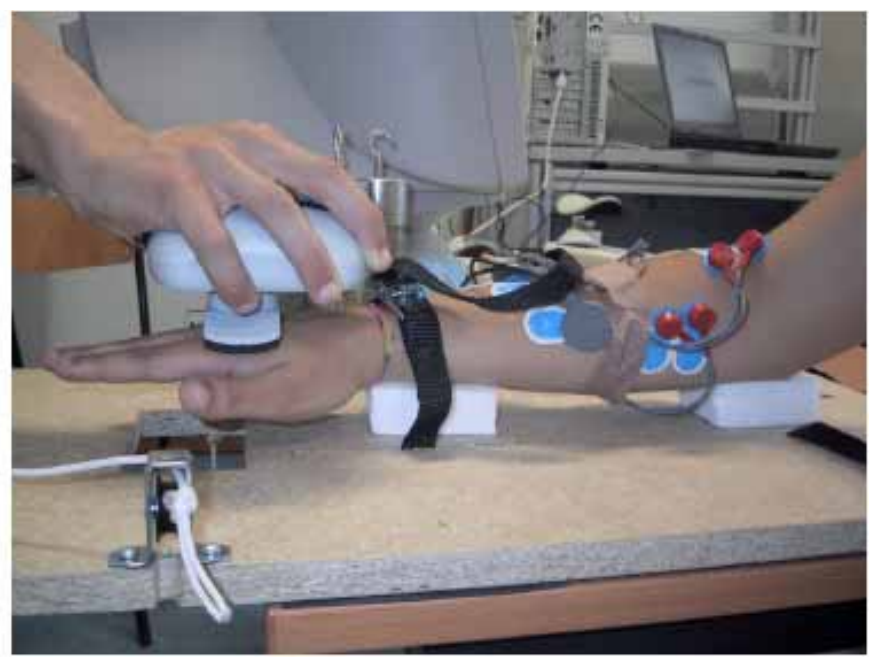



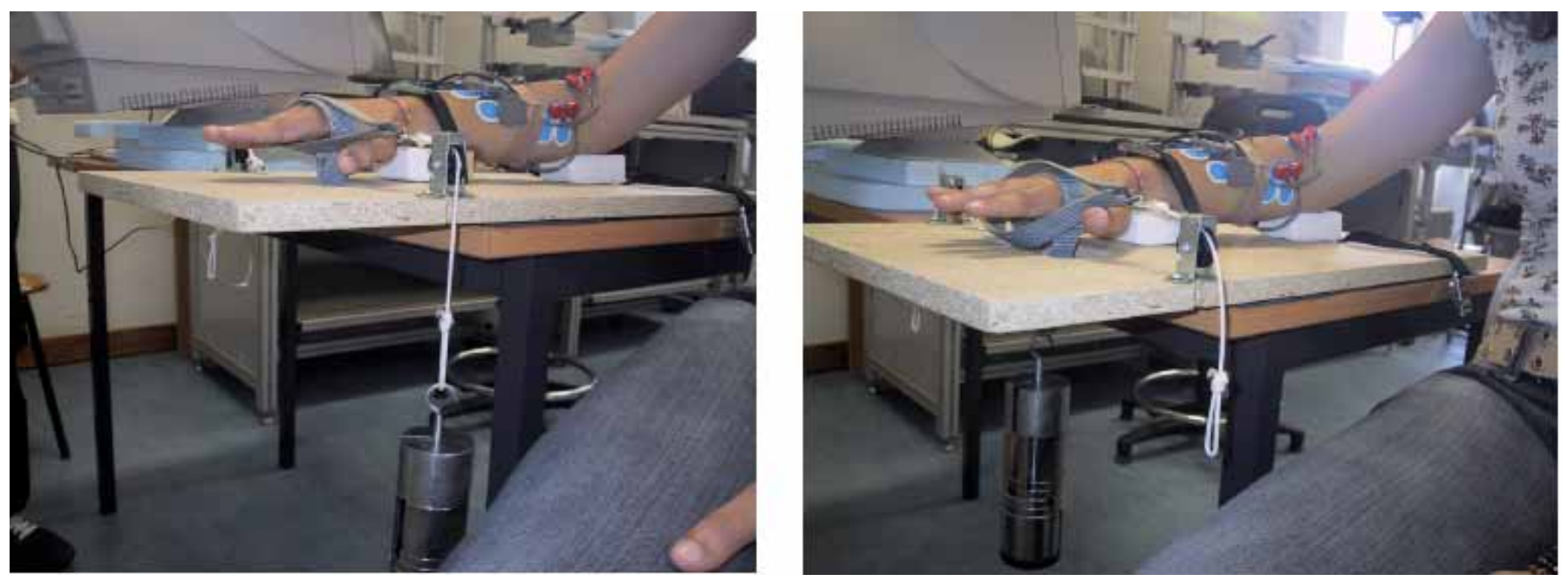

Fig. (6). The sub maximum isometric tests.

extension effort), (2) in the horizontal-left direction (to provoke a wrist cubital deviation effort) and (3) in the horizontal-right direction (to provoke a wrist radial deviation effort).

Two different efforts were simultaneously applied in the carpometacarpal joint: (4) vertical direction and horizontalleft direction (to provoke a wrist extension with a cubital deviation effort) and (5) vertical direction and horizontalright direction (to provoke a wrist extension with a radial deviation effort). A constant force of $2 \mathrm{~kg}$ was applied in each direction. To each effort protocol, three trials of isometric contractions tests were maintained during $\sim 10 \mathrm{~s}$, with a rest period of $\sim 2$ min between trials. The subjects were instructed to maintain the hand horizontal, face down, extended and aligned with the forearm direction, during the tests. EMG data was recorded in the three muscles.

\subsubsection{The Contraction Levels in the Forearm Muscles when Operating Different Mice}

After the MVE and RVE tests, each participant sequentially executed the three directions protocol, by the following order: vertical descending, vertical ascending, horizontal left-right, horizontal right-left, diagonal ascending and diagonal descending (see Fig. 3). The protocol of movements was executed with the low, medium and high friction force pairs.

Before executing the protocol of movements, it was asked the participants to rest the forearm on the table, assuming a normal working posture (Fig. 7). The EMG contraction levels in the forearm muscles during this resting posture was considered the zero-base line to the contraction levels during the mouse movement's protocol.

An EMG file was saved to each subject, including data from the three directions protocol. Marks were registered in the EMG file, in order to identify the instants of continuous movements (for example lines 1-8 in Fig. 3). EMG data corresponding to periods with changes in mouse displacement directions (descending to ascending, for example) and EMG data corresponding to changes in the protocol directions (vertical to horizontal and to diagonal for example) was not considered in the analysis.

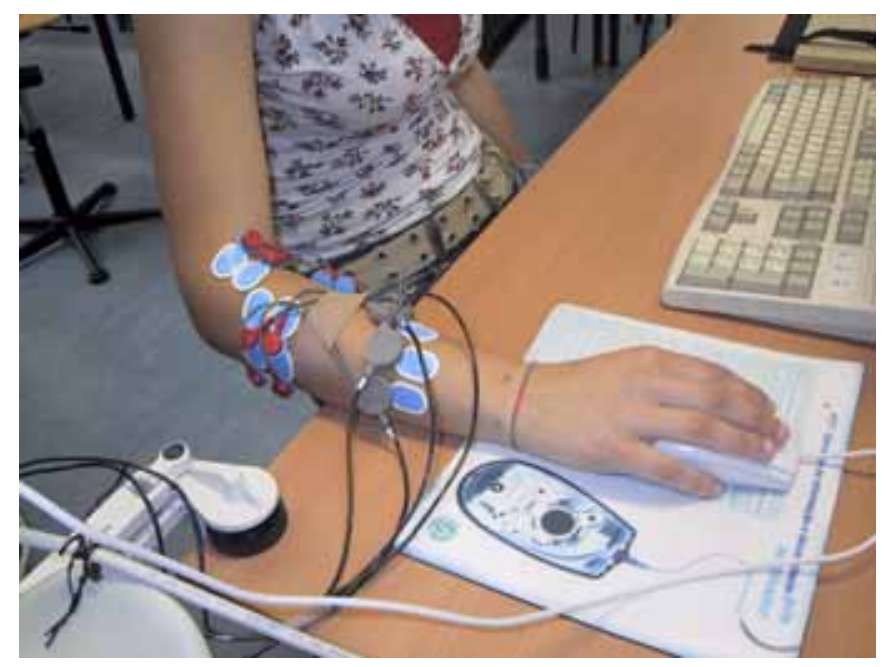

Fig. (7). The forearm posture during the protocol of movements.

\subsection{The Subjects Self-Perception of the Displacement Mouse-Pad}

It was applied a semantic, seven interval measurement scale, with a brief description associated with each category. It was asked the subjects to select the appropriate category to each pair mouse-pad. The objective was to evaluate the selfperception of the subjects regarding the easiness of displacement (or movement) of the mouse on the pad: "How easy or difficult do you find the displacement (or the movement) between the mouse and the pad, during the operations you have performed? Please, select one category to each pair mouse-pad".

The scale values ranged from 1 to 7: Very easy (score 1), Easy (score 2), Quite easy (score 3), Neither (score 4), Quite hard (score 5), Hard (score 6) and Very Hard (score 7) (Table 2).

\section{RESULTS}

4.1. The Measurement of Compression Forces of the Hand on the Mice During the Mice Movements Protocol

To each protocol (vertical, horizontal and diagonal) 8 readings of the compression force of the hand on the mice 
were recorded, when the mouse displacement was in the middle of the segments (see Fig. 3). Consequently, 24 compression force readings were recorded to each mouse. Considering a sampling of 17 subjects, the total number of readings to each mouse was 408 (Table $\mathbf{3}$ ).

Table 2. The Measurement Scale to Evaluate the Subjects Self-Perception Regarding the Easiness of Displacement Mouse-Pad

\begin{tabular}{|c|c|c|c|c|c|c|c|}
\hline $\begin{array}{c}\text { Mouse-Pad } \\
\text { Pairs }\end{array}$ & $\begin{array}{c}\text { Very } \\
\text { Easy }\end{array}$ & Easy & $\begin{array}{c}\text { Quite } \\
\text { Easy }\end{array}$ & Neither & $\begin{array}{c}\text { Quite } \\
\text { Hard }\end{array}$ & Hard & $\begin{array}{c}\text { Very } \\
\text { Hard }\end{array}$ \\
\hline \hline Pair 1 & O & O & O & O & O & O & O \\
\hline Pair 2 & O & O & O & O & O & O & O \\
\hline Pair 3 & O & O & O & O & O & O & O \\
\hline
\end{tabular}

friction force mouse-pad to the percentiles P61-P92 (Table 6).

\section{4 .The Maximum Isometric Tests}

Three protocol tests were used to evaluate the maximum voluntary EMG signal (MVE) in the different muscles: (1) Maximum dorsal wrist extension - mean measured exerted force of $11.0 \mathrm{~kg}$ (7.2-17.9, $\mathrm{SD}=3.5)$ (2) Maximum dorsal wrist extension simultaneously with maximum radial wrist deviation - mean measured force of $10.5 \mathrm{~kg}$ (7.6-15.7; $\mathrm{SD}=2.6$ ); (3) Maximum dorsal wrist extension simultaneously with maximum cubital wrist deviation mean measured force of $10.2 \mathrm{~kg}$ (6.6-13.5, SD=2.5). EMG data was recorded in each muscle to the different protocols (Table 7).

The EMG signal was normalized to the maximum contraction level in each muscle (MVE), in order to evaluate

Table 3. The Compression Force Mouse-Pad During the Mouse Movement'S Protocol

\begin{tabular}{|c|c|c|c|}
\hline Compression Force Mouse-Pad & $\begin{array}{c}\text { Low Friction Force Pair } \\
(\mathbf{n = 4 0 8})(\mathbf{g})\end{array}$ & $\begin{array}{c}\text { Medium Friction Force Pair } \\
(\mathbf{n = 4 0 8})(\mathbf{g})\end{array}$ & $\begin{array}{c}\text { High Friction Force Pair } \\
(\mathbf{n}=\mathbf{4 0 8})(\mathbf{g})\end{array}$ \\
\hline \hline Mean & ${ }^{1} 167$ & ${ }^{2} 159$ & 67 \\
\hline SD & 103 & 1098 & 67 \\
\hline Maximum & 950 & 16 & 476 \\
\hline Minimum & 34 & 22 \\
\hline
\end{tabular}

${ }^{2}$ Significant differences $(\mathrm{p}<0.001)$ between the friction forces in different mice.

Non-parametric Wilcoxon Signed-Rank test for two samples (SPSS - version 16 for Windows).

\subsection{The Evaluation of the Static Friction Force Mouse- Pad}

The static friction force of the different pairs mouse-pad was evaluated in two displacement directions: in the longitudinal direction (forearm direction) and in the transversal direction (perpendicular to forearm direction). To each direction, the static friction force was measured with the mice subjected to their own weight and subjected to an additional compression force of $100 \mathrm{~g}$. To the three selected pairs mouse-pad, friction forces were calculated with compression forces of $100 \mathrm{~g}, 150 \mathrm{~g}$ and $200 \mathrm{~g}$. The following symbols were used to the friction forces measured in the longitudinal direction of the mice: $F_{L, 0}-F_{L, 100}-F_{L, 150}-F_{L, 200}$. The next symbols were used to the friction forces mice-pads, measured in the transversal direction of the mice: $\mathrm{F}_{\mathrm{T}, 0}-\mathrm{F}_{\mathrm{T}, 100}$ - $\mathrm{F}_{\mathrm{T}, 150}-\mathrm{F}_{\mathrm{T}, 200}$ (Table 4).

\subsection{The Selected Mice-Pads}

Three pairs mice-pads were selected to test the forearm efforts during mouse operations. The criterion was to select pairs representative of low, medium and high friction force (Table 5). The high friction force mouse-pad has friction forces similar to the maximum or to P95 values found in the mice-pads sample $(n=39)$.

Considering the friction force distribution in the 39 micepads evaluated (Table 5), the low friction force mouse-pad corresponds to the percentiles P11-P24, the medium friction force mouse-pad to the percentiles P29-P59 and in the high the contraction levels during mouse operations. Based on the results of Table 7 the following protocols were selected to normalize MVE signal in each muscle:

- M. extensor digitorum: Dorsal extension

- M. extensor carpi ulnaris: Dorsal extension + cubital deviation

- M. extensor carpi radialis longus: Dorsal extension + radial deviation

Table 4. The Static Friction Force in Different Mice-Pads Pairs $(\mathbf{n}=39)$

\begin{tabular}{|c|c|c|c|c|}
\hline Friction Force & $\mathbf{F}_{\mathbf{L}, \mathbf{0}}(\mathbf{g})$ & $\mathbf{F}_{\mathbf{T}, \mathbf{0}}(\mathbf{g})$ & $\mathbf{F}_{\mathbf{L}, \mathbf{1 0 0}}(\mathbf{g})$ & $\mathbf{F}_{\mathbf{T}, \mathbf{1 0 0}}(\mathbf{g})$ \\
\hline \hline Maximum & 62 & 47 & 103 & 96 \\
\hline Minimum & 7 & 5 & 21 & 21 \\
\hline Mean & 28.0 & 24.8 & 56.0 & 52.2 \\
\hline P95 & 42.2 & 41.2 & 83.4 & 87 \\
\hline P5 & 12.8 & 12.8 & 24.7 & 24.7 \\
\hline P50 & 30.0 & 25.0 & 54.0 & 50.0 \\
\hline
\end{tabular}

\subsection{The Sub Maximal Isometric Tests}

Five protocol tests were used to evaluate the relative voluntary EMG signal (RVE) in the different muscles: (1) a force of $2 \mathrm{~kg}$ was applied in the vertical direction (to provoke a wrist extension effort), (2) a force of $2 \mathrm{~kg}$ was applied in 
Table 5. The Characteristics of the Selected Mice-Pads Pairs

\begin{tabular}{|c|c|c|c|}
\hline Mice-Pads Characteristics & Low Friction Force Pair & Medium Friction Force Pair & High Friction Force Pair \\
\hline PS/2-USB Ball-optical & PS/2 - optical & PS/2 - optical & $\mathrm{PS} / 2$ - ball \\
\hline $\mathrm{F}_{\mathrm{L} 0}-\mathrm{F}_{\mathrm{T}, 0}(\mathrm{~g})$ & $18-18$ & $21-21$ & $42-28$ \\
\hline $\mathrm{F}_{\mathrm{L}, 100}-\mathrm{F}_{\mathrm{T}, 100}(\mathrm{~g})$ & $34-34$ & $54-54$ & $79-77$ \\
\hline $\mathrm{F}_{\mathrm{L}, 150}-\mathrm{F}_{\mathrm{T}, 150}(\mathrm{~g})$ & $54-45$ & $57-57$ & $97-85$ \\
\hline $\mathrm{F}_{\mathrm{L}, 200}-\mathrm{F}_{\mathrm{T}, 200}(\mathrm{~g})$ & $63-51$ & $86-65$ & $115-107$ \\
\hline $\begin{array}{c}\text { Buttons } \\
\text { Scroll wheel }\end{array}$ & $\begin{array}{c}2 \text { button } \\
1 \text { scroll wheel }\end{array}$ & $\begin{array}{c}2 \text { button } \\
1 \text { scroll wheel }\end{array}$ & $\begin{array}{c}2 \text { button } \\
1 \text { scroll wheel }\end{array}$ \\
\hline Manufacturing year & 2007 & 2002 & 2001 \\
\hline $\begin{array}{c}\text { Weight }(\mathrm{g}) \\
\text { Height-length-width-button width }\end{array}$ & $\begin{array}{c}65 \\
38-121-57-62\end{array}$ & $\begin{array}{c}69 \\
37-116-59-59\end{array}$ & $\begin{array}{c}90 \\
30-110-70-50\end{array}$ \\
\hline Contact surface mouse-pad & $\begin{array}{l}4 \text { elliptical areas } \\
\text { Axles } 14 / 4 \mathrm{~mm}\end{array}$ & $\begin{array}{l}4 \text { elliptical areas } \\
\text { Axles } 14 / 6 \mathrm{~mm}\end{array}$ & $\begin{array}{c}4 \text { circular areas } \\
\text { Diameter } \varnothing 6 \mathrm{~mm}\end{array}$ \\
\hline
\end{tabular}

Table 6. The Friction Force Mouse-Pad Distribution Percentiles for the 3 Selected Mice-Pads Pairs

\begin{tabular}{|c|c|c|c|}
\hline Mice-Pads Characteristics & Low Friction Force Pair & Medium Friction Force Pair & High Friction Force Pair \\
\hline \hline $\mathrm{F}_{\mathrm{L}, 0}-\mathrm{F}_{\mathrm{T}, 0}(\mathrm{~g})$ & $18-18$ & $21-21$ & $42-28$ \\
$\mathrm{~F}_{\mathrm{L}, 0}-\mathrm{F}_{\mathrm{T}, 0}($ percentile $)$ & $\mathrm{P} 21-\mathrm{P} 24$ & $\mathrm{P} 29-\mathrm{P} 34$ & $\mathrm{P} 92-\mathrm{P} 61$ \\
\hline $\mathrm{F}_{\mathrm{L}, 100}-\mathrm{F}_{\mathrm{T}, 100}(\mathrm{~g})$ & $34-34$ & $54-54$ & $79-77$ \\
$\mathrm{~F}_{\mathrm{L}, 100}-\mathrm{F}_{\mathrm{T}, 100}(\mathrm{percentile})$ & $\mathrm{P} 11-\mathrm{P} 16$ & $\mathrm{P} 50-\mathrm{P} 58$ & $\mathrm{P} 89-\mathrm{P} 92$ \\
\hline
\end{tabular}

Table 7. The MVE Protocol Tests and the EMG Readings in Each Muscle $(\mu V)$ for the Subjects $(n=17)$

\begin{tabular}{|c|c|c|c|}
\hline MVE Protocol Tests & $\begin{array}{c}\operatorname{MVE}_{\text {ED }}(\mu \mathrm{V}) \\
\text { Mean (Range, SD) }\end{array}$ & $\begin{array}{c}\operatorname{MVE}_{\text {ECU }}(\mu \mathrm{V}) \\
\text { Mean (Range, SD) }\end{array}$ & $\begin{array}{c}\operatorname{MVE}_{\text {ECRL }}(\mu \mathrm{V}) \\
\text { Mean (Range, SD) }\end{array}$ \\
\hline Dorsal extension & ${ }^{1} \underline{\mathbf{3 6 0}}(208-636,139)$ & $266(123-543,113)$ & $271(110-675,162)$ \\
\hline $\begin{array}{l}\text { Dorsal extension + } \\
+ \text { radial deviation }\end{array}$ & $302(140-529,116)$ & $175(34-469,107)$ & $\underline{\mathbf{3 4 9}}(106-755,181)$ \\
\hline $\begin{array}{l}\text { Dorsal extension + } \\
+ \text { cubital deviation }\end{array}$ & ${ }^{1} 349(175-660,141)$ & $\underline{\mathbf{3 3 7}}(177-643,121)$ & $203(45-453,115)$ \\
\hline
\end{tabular}

Significant differences $(\mathrm{p}<0.05)$ between MVE values resulting from different protocols in the same muscle, except for the values $\left({ }^{1}\right)$ ( $\left.p>0.05\right)$.

Non-parametric Wilcoxon Signed-Rank test for two samples (SPSS - version 16 for Windows).

the horizontal-left direction (to provoke a wrist cubital deviation effort), (3) a force of $2 \mathrm{~kg}$ was applied in the horizontal-right direction (to provoke a wrist radial deviation effort), (4) a force of $2 \mathrm{~kg}$ was applied in the horizontal-left direction, simultaneously with a force of $2 \mathrm{~kg}$ in the vertical direction (to provoke a wrist extension + cubital deviation effort) and finally (5) a force of $2 \mathrm{~kg}$ was applied in the horizontal-right direction, simultaneously with a force of 2 $\mathrm{kg}$ in the vertical direction (to provoke a wrist extension + radial deviation effort). EMG data was recorded in the four muscles (Table 8).

The EMG signal was normalized to the relative contraction level in each muscle (RVE), in order to compare contraction levels in different muscles during mouse operations. During the execution of the different protocols for the subjects $(n=17)$, the relative voluntary contraction tests revealed a higher data consistency than the maximum contraction tests (the intensity of the effort was constant during data collection and the isometric contractions was maintained during $\sim 10 \mathrm{~s}$ in each trial).

Based on the results of Table 8. the following protocols were selected to normalize RVE signal in each muscle:

- M. extensor digitorum: Dorsal extension

- M. extensor carpi ulnaris: Dorsal extension + cubital deviation

- M. extensor carpi radialis longus: Dorsal extension + radial deviation

\subsection{The Contraction Levels in the Forearm Muscles} when Operating Different Mice

Each participant executed the three directions protocol, with the low, medium and high friction force pairs. 
Table 8. The RVE Protocol Tests and the EMG Readings in Each Muscle $(\mu V)$ for the Subjects $(n=17)$

\begin{tabular}{|c|c|c|c|}
\hline RVE Protocol Tests & $\begin{array}{c}\operatorname{RVE}_{\mathrm{ED}}(\mu \mathrm{V}) \\
\text { Mean (Range, SD) }\end{array}$ & $\begin{array}{c}\mathbf{R V E}_{\text {ECU }}(\mu \mathrm{V}) \\
\text { Mean (Range, SD) }\end{array}$ & $\begin{array}{c}\operatorname{RVE}_{\text {ECRL }}(\mu \mathrm{V}) \\
\text { Mean (Range, SD) }\end{array}$ \\
\hline Dorsal extension & ${ }^{1} \underline{\mathbf{7 6}}(21-133,27)$ & $5,690(15-174,37)$ & $7,837(0-78,22)$ \\
\hline Radial deviation & ${ }^{2} 40(7-104,22)$ & $23(3-53,15)$ & ${ }^{8} 32(0-63,17)$ \\
\hline Cubital deviation & ${ }^{2} 49(19-142,31)$ & $89(24-176,35)$ & $12(0-28,8)$ \\
\hline
\end{tabular}

Contraction levels were calculated as a proportion of the maximum level (MVE, see paragraph 3.4) and also as a proportion of the sub maximal contraction level (RVE, see paragraph 3.5).

Forearm muscles contraction as a proportion of MVE was calculated summarizing the three mouse movement's protocol: vertical, horizontal and diagonal directions (Table 9).

\subsection{The Subjects Perception of Mouse-Pad Displacement Easiness}

The self-perception of the subjects regarding the easiness of the mice displacement (or movement) was evaluated according to a seven interval semantic scale (see Table 11).

The subjects considered the low friction force mouse-pad a Very easy-Easy displacement pair; the medium friction force mouse-pad was considered Neither-Quite hard displacement pair; the high friction force mouse-pad was also considered a Neither-Quite hard displacement pair. No significant differences were found between the medium and high friction pairs (Table 11).

\section{CONCLUSION}

A standard protocol of mouse movements was performed involving horizontal, vertical and diagonal mouse displacements. The protocol involved active displacement of the mouse in the pad, similar to the movements performed during drawing applications.

The movements protocol were performed with three pairs mouse-pad, classified as low, medium and high friction force pairs. The mean longitudinal static friction force measured in different mice-pad pairs $(n=39)$ was $28 \mathrm{~g}$ (7-62) without an external compression force in the mice and $56.0 \mathrm{~g}$ (21-103) with an external compression force of $100 \mathrm{~g}$. The longitudinal friction force of the three selected pairs, representative of low, medium and high friction force pairs, with a compression force of $100 \mathrm{~g}$ was respectively 34,54 and $79 \mathrm{~g}$. The longitudinal static friction force in the three selected mice, measured with $100 \mathrm{~g}$ compression force, corresponded to a P11, P50 and P89 percentiles in the friction force distribution of the 39 pairs measured.

The three pairs were selected from a sampling of 39 pairs actually in use in office workplaces. The differences in the

Table 9. The Mean, P10 and P90 Contraction Levels (\% MVE) in the Different Muscles During Operations with the 3 Selected Mice-Pads Pairs - Composition of Horizontal, Vertical and Diagonal Movements Protocols (n=17 Subjects)

\begin{tabular}{|c|c|c|c|}
\hline Mice-Pads Characteristics & Low Friction Force Pair (\% MVE) & Medium Friction Force Pair (\% MVE) & High Friction Force Pair (\% MVE) \\
\hline \multicolumn{4}{|l|}{ P10 (Range; SD) (\% MVE) } \\
\hline M. extensor carpi ulnaris & $10.6(4-18,4.0)$ & $11.0(5-21,4.3)$ & $10.4(5-21,4.3)$ \\
\hline M. extensor carpi radialis 1 . & $7.6(3-18,4.0)$ & $7.9(3-18,3.8)$ & $7.5(3-17,3.8)$ \\
\hline M. extensor digitorum & ${ }^{1} \underline{\mathbf{1 2 . 3}}(6-19,4.7)$ & $12.1(6-20,4.4)$ & ${ }^{1} \underline{\mathbf{1 3 . 3}}(6-25,5.4)$ \\
\hline M. extensor carpi ulnaris & ${ }^{2,3} \mathbf{1 5 . 9}(7-29,5.7)$ & ${ }^{3} 17.6(10-33,5.8)$ & ${ }^{2} \underline{\mathbf{1 7 . 4}}(9-31,6.3)$ \\
\hline M. extensor carpi radialis 1 . & $9.1(3-20,4.4)$ & $10.5(4-22,5,3)$ & $9.3(4-19,3.9)$ \\
\hline \multicolumn{4}{|l|}{ P90 (Range; SD) (\%MVE) } \\
\hline
\end{tabular}

${ }_{1,2,3}$ Significant differences $(\mathrm{p}<0.05)$ between \%MVE values resulting from movements in pairs mouse-pad with different friction forces.

Non-parametric Wilcoxon Signed-Rank test for two samples (SPSS - version 16 for Windows)

The mean forearm muscles contraction as a proportion of RVE was calculated to each movement direction and also combining the three mouse movement's protocol (vertical, horizontal and diagonal directions) (Table 10). 
Table 10. The Mean Relative Contraction Levels to Each Movement Direction (\% RVE) in the Different Muscles During Operations with the 3 Selected Mice-Pads Pairs (n=17 Subjects)

\begin{tabular}{|c|c|c|c|}
\hline Mice-Pads Characteristics & $\begin{array}{c}\text { Low Friction Force Pair (\% RVE) } \\
\text { Mean (Range, SD) }\end{array}$ & $\begin{array}{c}\text { Medium Friction Force Pair (\% RVE) } \\
\text { Mean (Range, SD) }\end{array}$ & $\begin{array}{c}\text { High Friction Force Pair (\% RVE) } \\
\text { Mean (Range, SD) }\end{array}$ \\
\hline \multicolumn{4}{|l|}{ Horizontal Movements } \\
\hline M. extensor digitorum & ${ }^{4} 49.2(29-101,21.0)$ & $52.2(32-97,19.3)$ & ${ }^{4} 53.8(28-110,21.1)$ \\
\hline M. extensor carpi ulnaris & ${ }^{6} 36.9(14-70,16.8)$ & $41.8(17-68,17.2)$ & ${ }^{6} 42.3(21-69,16.2)$ \\
\hline M. extensor carpi radialis 1. & ${ }^{5,7} 41.3(21-105,19.5)$ & ${ }^{7} 43.4(22-105,19.0)$ & ${ }^{5} 44.8(24-103,18.7)$ \\
\hline M. extensor digitorum & $43.9(22-82,14.8)$ & $43.9(25-74,13.4)$ & $48.3(25-114,21.9)$ \\
\hline M. extensor carpi ulnaris & $36.7(16-66,13.7)$ & ${ }^{3} 34.8(15-58,14.0)$ & ${ }^{3} 37.9(17-56,13.3)$ \\
\hline M. extensor carpi radialis 1. & $39.7(22-80,13.9)$ & $41.5(22-109,20.5)$ & $41.6(22-104,19.2)$ \\
\hline \multicolumn{4}{|l|}{ Diagonal Movements } \\
\hline M. extensor carpi radialis 1 . & $42.4(22-107,19.8)$ & $42.4(21-118,22.4)$ & $41.4(21-102,18.7)$ \\
\hline \multicolumn{4}{|c|}{ Combination of Horizontal, Vertical and Diagonal Movements } \\
\hline M. extensor digitorum & ${ }^{1} \underline{46.9}(28-80,16.6)$ & $47.8(29-79,16.4)$ & ${ }^{1} \underline{\mathbf{5 0 . 4}}(28-100,18.9)$ \\
\hline M. extensor carpi ulnaris & ${ }^{8} 36.3(15-64,14.1)$ & $37.9(16-61,13.9)$ & ${ }^{8} 39.5(18-61,14.8)$ \\
\hline M. extensor carpi radialis 1. & ${ }^{2} \underline{41.6}(21-107,19.8)$ & $42.6(22-110,20.4)$ & ${ }^{2} \underline{42.9}(23-103,18.7)$ \\
\hline
\end{tabular}

${ }_{1,2,3}$ Significant differences $(\mathrm{p}<0.05)$ between \%RVE values resulting from operations in pairs mouse-pad with different friction forces.

${ }_{4,5,6,7,8}$ Significant differences $(\mathrm{p}<0.001)$ between $\%$ RVE values resulting from operations in pairs mouse-pad with different friction forces.

Non-parametric Wilcoxon Signed-Rank test for two samples (SPSS - version 16 for Windows).

Table 11. The Self-Perception of the Subjects $(n=17)$ Regarding the Easiness of Displacement Mouse-Pad

\begin{tabular}{|c|c|c|c|}
\hline Mice-Pads Characteristics & Low Friction Force Pair & Medium Friction Force Pair & High Friction Force Pair \\
\hline \hline $\begin{array}{c}\text { Self-perception scores (1-7) } \\
\text { Mean (range, SD) }\end{array}$ & ${ }^{1,2} 1.4(1-2,0.49)$ & ${ }^{1} 4.4(2-6,1.2)$ & ${ }^{2} 4.7(2-7,1.4)$ \\
\hline
\end{tabular}

The scale values: (1) Very easy, (2) Easy, (3) Quite easy, (4) Neither, (5) Quite hard, (6) Hard (7) Very Hard.

${ }^{1,2}$ Significant differences $(\mathrm{p}<0.001)$ between self-perception scores.

Non-parametric Wilcoxon Signed-Rank test for two samples (SPSS - version 16 for Windows).

easiness of displacement mouse-pad in the three selected pairs were sensitive to the participants. The low friction force mouse-pad was rated as Very easy-Easy (and the medium and high friction force mouse-pad rated as NeitherQuiet hard.

Mean values of $12.6 \% \mathrm{MVE}, 17.0 \% \mathrm{MVE}$ and $9.7 \% \mathrm{MVE}$ were found in the M. extensor digitorum, in the M. extensor carpi ulnaris and in the $M$. extensor carpi radialis longus respectively when performing the movements' protocol ( $\sim 138 \mathrm{~s})$ with the three pairs mouse-pad. M. extensor carpi ulnaris was the muscle with highest contraction levels during mice operations.

A $8,1 \%$ increase in \%MVE values was observed in the M. extensor digitorum and a 9,4\% increase in \%MVE was observed in the $M$. extensor carpi ulnaris when the high friction force pair was operated, relatively to the low friction force pair $(\mathrm{p}<0.05)$. Non significant differences were found in the M. extensor carpi radialis longus.
Regarding \%RVE contraction values, an increase of $7.5 \%, 8.8 \%$ and $3.1 \%$ was observed respectively in the $M$. extensor digitorum, in the $M$. extensor carpi ulnaris and in the $M$. extensor carpi radialis longus when the high friction force pair was operated, relatively to the low friction force pair $(\mathrm{p}<0.05)$. The difference was particularly observed when performing horizontal movements with the mice $(9.3 \%, 14.6 \%$ and $8.5 \%$ increase respectively $(\mathrm{p}<0.001))$.

The main conclusions of this study is that operating a high friction force mouse-pad (79 $\mathrm{g}$ of static longitudinal friction force, measured with a compression force of $100 \mathrm{~g}$ on the mouse) may increase the risk to symptoms or disorders in the wrist due to an increase in the forearm muscles contraction levels, particularly in operations involving intensive mouse displacements (drawing applications).

The drag-and-drop gesture is widespread in drawing applications, where the user presses the mouse button while the mouse cursor hovers over an interface object, the cursor is moved (the mouse is displaced) to a different location 
while holding the button down and the mouse button released.

In this sense, when selecting a computer mouse to work with drawing applications like CAD work, particular attention must be paid to the characteristics of the mouse contact surface with the pad as well as with the characteristics of the pad surface, both in terms of the static and sliding coefficient of friction. For dry low surface pressures the friction force is directly proportional to the pressure between the mouse and the pad. Also, as the surface pressure rises the friction factor rises slightly. In this sense, operators working with drawing applications should be particularly instructed to reduce the vertical force applied by the hand on the mouse during mouse work.

\section{REFERENCES}

[1] Fagarasanu M, Kumar S. Carpal tunnel syndrome due to keyboarding and mouse tasks: a review. Int J Ind Ergon 2003; 31: 119-36.

[2] Karlqvist L, Hagberg M, Selin K. Variation in upper limb posture and movement during word processing with and without mouse use. Ergonomics 1994; 37: 1261-67.

[3] Johnson PW, Hagberg M, Wigaeus HE, Rempel D. Measuring and characterizing force exposures during computer mouse use. Scand $\mathbf{J}$ Work Environ Health 2000; 26(5): 398-405.

[4] Laursen B, Jensen BR, Garde AH, Jørgensen AH. Effect of mental and physical demands on muscular activity during the use of a computer mouse and a keyboard. Scand J Work Environ Health 2002; 28(4): 215-21.

[5] Karlqvist L, Hagberg M, Koster K, Wenemark W, Anell R. Musculoskeletal symptoms among computer-assisted design (CAD) operators and evaluation of a self-assessment questionnaire. Int J Occup Environ Health 1996; 2(3): 185-94.

[6] Jensen C, Borg V, Finsen L, Hansen K, Juul-Kristensen B, Christensen H. Job demands, muscle activity and musculoskeletal symptoms in relation to work with the computer mouse. Scand $\mathbf{J}$ Work Environ Health 1998; 24(5): 418-24.

[7] Jensen C, Finsen L, Sogaard K, Christensen H. Musculoskeletal symptoms and duration of computer and mouse use. Int J Ind Ergon 2002; 30: 265-75.
[8] Armstrong TJ, Martin BJ, Franzblau A, Rempel DM, Johnson PW. Mouse input devices and work-related upper limb disorder. In: Grieco A, Molteni G, Occhipinti E, Piccoli B, Eds. Work with Display Units 1994. Amsterdam: Elsevier Science 1995; pp. 37580.

[9] Punnett L, Bergqvist U. Visual display unit work and upper extremity musculoskeletal disorders: a review of epidemiologic findings. Solna Sweden: National Institute of Working Life, Arbete och Hälsa 1997; vol. 16: pp. 1-161.

[10] Keir PJ, Bach JM, Rempel D. Effects of computer mouse design and task on carpal tunnel pressure. Ergonomics 1999; 42: 1350-60.

[11] Jensen C. Development of neck and hand-wrist symptoms in relation to duration of computer use at work. Scand J Work Environ Health 2003; 29(3): 197-205.

[12] Blatter BM, Bongers PM. Duration of computer use and mouse use in relation to musculoskeletal disorders of neck or upper limb. Int J Ind Ergon 2002; 30: 295-306.

[13] Villagea J, Rempel D, Teschke K. Musculoskeletal disorders of the upper extremity associated with computer work: a systematic review. Occup Ergon 2005; 5: 205-18.

[14] Gerr F, Marcus M, Ensor C, et al. A prospective study of computer users: I. study design and incidence of musculoskeletal symptoms and disorders. Am J Ind Med 2002; 41(4): 221-35.

[15] Lassen CF, Mikkelsen S, Kryger A, et al. Elbow and wrist/hand symptoms among 6943 computer operators. A 1-year follow-up study (the NUDATA study). Am J Ind Med 2004; 46: 521-33.

[16] Birch L, Juul-Kristensen B, Jensen C, Finsen L, Christensen H. Acute response to precision, time pressure and mental demand during simulated computer work. Scand J Work Environ Health 2000; 26(4): 299-305.

[17] Visser B, De Looze M, De Graaff M, Van Dieën J. Effects of precision demands and mental pressure on muscle activation and hand forces in computer mouse tasks. Ergonomics 2004; 47(2): 202-17.

[18] Bystrom JU, Hansson GA, Rylander L, Ohlsson K, Kallrot G, Skerfving S. Physical workload on neck and upper limb using two CAD applications. Appl Ergon 2002; 33(1): 63-4.

[19] Zipp P. Recommendations for the standardization of lead positions in surface electromyography. Eur J Appl Physiol 1982; 50: 41-4.

[20] Soderberg GL. Selected topics in surface electromyography for use in the occupational setting: expert perspectives. Rockville, MD: US Dept of Health and Human Services, Public Health Service 1992; Publication No. 91-100.

[21] Riek S, Carson RG, Wright A. A new technique for the selective recording of extensor carpi radialis longus and brevis EMG. J Electromyogr Kinesiol 2000; 10: 249-53. 